\title{
EVALUATION OF THE IMPACT OF CONSUMPTION, INVESTMENT AND EXPORT ON IMPORT - DATA FROM GERMAN ECONOMY
}

\author{
M. Ivanova ${ }^{1}$, L. Dospatliev ${ }^{2}$ \\ ${ }^{1}$ Department of Informatics and Mathematics \\ Faculty of Economics \\ Trakia University \\ Studentski Grad, Stara Zagora, 6000, BULGARIA \\ ${ }^{2}$ Department of Pharmacology \\ Animal Physiology and Physiological Chemistry \\ Faculty of Veterinary Medicine \\ Trakia University \\ Studentski Grad, Stara Zagora, 6000, BULGARIA
}

\begin{abstract}
German import represents 5.6\% of total global imports and this establishes Germany as the third largest importer in the world. This study examines the dependence of imports on consumption, investment and exports in Germany, using time series data for the period 1997-2013. We received an error correction model that involved short-term and long-term effects and seasonal components. Based on the estimated model, with $1 \%$ increase in investment or exports the short-term effect would result in an increase in imports by $0.39 \%$ and $0.58 \%$, respectively. We determined the period for which there would be a balance of imports in case of shock on independent variables. There is also a slight constant change in imports during different seasons and a general reduction of import growth by $5.59 \%$ on average.
\end{abstract}

AMS Subject Classification: 62-07, 91B60, 91B64, 91B82

Key Words: import, consumption, investment, export, error correction model

$\begin{array}{lrc}\text { Received: } & 2017-06-14 & \text { (C) } 2017 \text { Academic Publications, Ltd. } \\ \text { Revised: } & 2017-11-15 & \text { url: www.acadpubl.eu } \\ \text { Published: } & \text { December } 23,2017 & \end{array}$




\section{Introduction}

The German import represents $5.6 \%$ of total global imports and this establishes Germany as the third largest importer in the world. Primary German import partners are European Union (54.8\%), China (8.9\%), US (5.5\%), Switzerland (4.2\%) and Russia (3.3\%).

The behaviour of the import function has been the subject matter of a number of empirical studies. One may mention the contributions by [19], [34], $[25],[18],[2],[42],[17],[5],[29],[36],[3],[14],[22],[23],[24],[41],[26],[32],[4]$.

According to numerous scholars, including [28], [40], [30], [37], [38], [13], [17], and [29], traditional models estimate import demand as a function of relative prices and income (GDP), omitting changes in foreign reserves. Most of these models assume that macroeconomic variables are stationary, but evidence indicates the contrary, namely, that macroeconomic time series are typically nonstationary, exhibiting high serial correlation between successive observations. This implies that the $t$ and $F$ tests are incorrect and lead to false conclusions and spurious regression problems (portrayed by a high $R^{2}$ value and a statistically significant Durbin-Watson statistic) (see [10], [12]).

The linkage between imports and exports, consumption and investment based on the cointegration method (whose focus focuses on the econometric implications of non-stationarity assumptions) have become a recent direction of research (see [1], [27], [39], [28], [20], [40], [15], [35], [30], [7], [8], [33], [37], [38], [39], [12]).

Given the importance of imports for Germany's economic development, and the ensuing implications, the central aim of this paper is to examine the dependence of imports on consumption, investment and exports in Germany, using time series data for the period 1997-2013.

\section{Data and Methodology}

\subsection{Data Description}

We used quarterly data Germany observations on import of goods and services, consumption, investment, and exports of goods and services. Quaterly data on all variables are available from 1997 to 2013 from World Development Indicators. All the variables are taken in their natural logarithms to avoid the problems of heteroscedasticity. 


\subsection{Statistical Software}

Statistical analysis and all chartings were performed within the R program. All statistical tests applied to the variables were obtained within attaching package 'rgive'.

\subsection{Model Specification}

This paper uses error correction model (ECM) to identify the dependence of imports on consumption, investment and exports in Germany. The long-run import function is specified as follows:

$$
\text { Im }_{t}=f\left(\text { Cons }_{t}, \text { Invest }_{t}, E x_{t}\right),
$$

where Im is import, Cons is consumption, Invest is investment and Ex is export, and $t$ is the time trend.

In an explicit and econometric form, using the log-linear form equation (1) can be stated as

$$
\ln I m_{t}=a_{0}+a_{1} \ln \text { Cons }_{t}+a_{2} \ln \text { Invest }_{t}+a_{3} \ln E x_{t}+\varepsilon_{t},
$$

where $\varepsilon_{t}$ is the i.i.d. error term at period $t, a_{0}$ is the constant term, and ln stands for natural logarithms. From economic theory, the signs for the coefficients $a_{1}$, $a_{2}$ and $a_{3}$ are expected to be positive.

To distinguish the short-run effects from the long-run trend, equation (2) must be specified in an error correction model (ECM) format following [31], which has been used in many recent studies, including [40], [7], [37], and [12]. Equation (2) is therefore rewritten in an ECM format in equation (3) below:

$$
\begin{aligned}
\Delta \text { Im }_{t} & =\beta_{0}+\sum_{i=1}^{n} \beta_{i} \Delta \ln \text { Im }_{t-i}+\sum_{i=0}^{n} \Delta \ln \text { Cons }_{t-i} \\
& +\sum_{i=0}^{n} \delta_{i} \Delta \ln \text { Invest }_{t-i}+\sum_{i=0}^{n} \eta_{i} \Delta \ln \text { Ex }_{t-i} \\
& +\lambda_{1} \ln \text { Im }_{t-1}+\lambda_{2} \ln \text { Cons }_{t-1}+\lambda_{3} \ln \text { Invest }_{t-1} \\
& +\lambda_{4} \ln E x_{t-1}+\omega_{t},
\end{aligned}
$$

all variables are defined as before, except the first difference operator, which is $\Delta$. 


\subsection{Statistical Tests}

\subsubsection{Ordinary Least Squares (OLS) method}

In econometrics, Ordinary Least Squares (OLS) method is widely used to estimate the parameter of a linear regression model. OLS estimators minimize the sum of the squared errors (a difference between observed values and predicted values). The OLS estimator is consistent when the regressors are exogenous, and optimal in the class of linear unbiased estimators when the errors are homoscedastic and serially uncorrelated. Under these conditions, the method of OLS provides minimum-variance mean-unbiased estimation when the errors have finite variances. Under the additional assumption that the errors are normally distributed, OLS is the maximum likelihood estimator.

\subsubsection{The Stationarity Test (Unit Root Test)}

In order to investigate the stationarity properties of the data, a univariate analysis of each of the four time series imports, consumption, investment, and exports, was carried out by testing for the presence of a unit root Augmented Dickey Fuller (ADF) (see [9]). The lag length for the ADF test was selected to ensure that the residuals were white noise.

\subsubsection{The Cointegration Test}

Cointegration, an econometric property of time series variable, is a precondition for the existence of a long run or equilibrium economic relationship between two or more variables having unit roots (i.e. integrated of order one). The Johansen approach can determine the number of co-integrated vectors for any given number of non-stationary variables of the same order. Two or more random variables are said to be cointegrated if each of the series are themselves non-stationary. This test may be regarded as a long run equilibrium relationship among the variables. The purpose of the Cointegration tests is to determine whether a group of non-stationary series is cointegrated or not.

\subsubsection{Breusch-Godfrey Test}

In statistics, the Breusch-Godfrey test, named after Trevor Breusch and Leslie Godfrey (see [6], [16]), is used to assess the validity of some of the modelling assumptions inherent in applying regression-like models to observed data series. 
In particular, it tests for the presence of serial correlation that has not been included in a proposed model structure and which, if present, would mean that incorrect conclusions would be drawn from other tests, or that sub-optimal estimates of model parameters are obtained if it is not taken into account. The regression models to which the test can be applied include cases where lagged values of the dependent variables are used as independent variables in the model's representation for later observations. This type of structure is common in econometric models. The null hypothesis is that there is no serial correlation.

\subsubsection{Jarque-Bera and Doornik-Hansen Tests}

The Jarque-Bera test (see [21]) is a popular test for univariate normality based on moments. The test statistic is the sum of the squares for the sample standardized third and fourth moments. This test is emphasized especially in econometrics to test normality. The null hypothesis for the test is that the data is normally distributed. The Jarque-Bera statistic is particularly suitable for large samples. For small sample sizes the test procedure by [11] was developed.

\subsubsection{White test}

In econometrics, an extremely common test for heteroscedasticity is the White test (see [43]), which begins by allowing the heteroscedasticity process to be a function of one or more of independent variables. The White test allows the independent variable to have a nonlinear and interactive effect on the error variance. The null hypothesis of White test of no heteroscedasticity against heteroscedasticity of unknown, general form.

\subsubsection{Nested test}

The Nested test is used to examine whether two models, one of which contains a subset of the variables contained in the other, are statistically equivalent in terms of their predictive capability. The null hypothesis for the test is that the two models are statistically equivalent in terms of their predictive capability. The alternative hypothesis would be that the full model contributes additional information about the association between the target and predictor variables. 


\section{Empirical Results}

The long-run trends of the variables included in the import function are shown in Figure 1. The time series $\ln I m$ (natural logarithm of import), ln Ex (natural logarithm of export) and ln Cons (natural logarithm of consumption) have an upward trend. No discernible trend is observed in the time series $\ln$ Invest (natural logarithm of investment). On Figure 1 presence of a pronounced seasonal component in time series $\ln$ Cons and $\ln$ Invest is observed whose period is 4 . This requires the inclusion of seasonality dummy variables in the model.

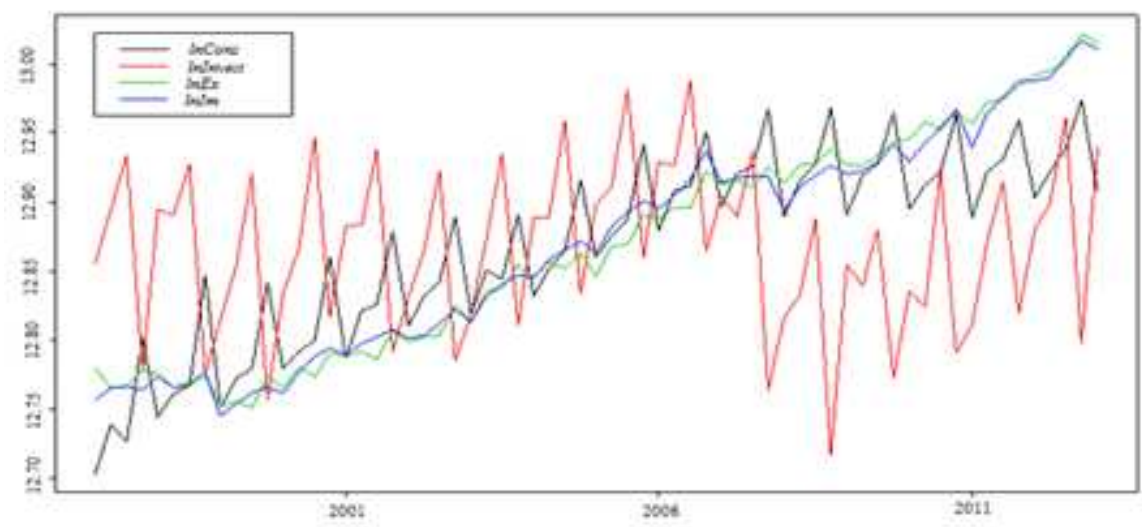

Figure 1: Time series plot of the variables

We began by investigating the stationarity properties of each of the four variables. Based on the results of the ADF test for the time series $\ln C$ ons with added 9 maximum lags and difference equal to 2 (Table 1), we accept that the time series $\ln C o n s$ is non-stationary and the order of integration is 2 .

Similarly, we found that the order of integration of time series $\ln E x$ also was 2, and the other two time series $\ln$ Invest and $\ln I m$ was integrated of order 1. Therefore, the time series $\ln C o n s, \ln E x, \ln$ Invest and $\ln I m$ need to be differentiated twice and once, respectively.

\subsection{Creating an Initial Model - Model 1}

In statistics, it is known that the number of lags added to each of the variables is desirable to be a number divided by the number of periods in the time series. Due to this, we added 8 lags to each of the four variables. That's how we 
Table 1: ADF test for the time series $\ln$ Cons with 9 maximum lags and difference $=2$.

\begin{tabular}{llll}
\hline D-lag & $t$-adf & $p$-value & AIC \\
\hline 9 & -2.954 & $3.866 \mathrm{e}-03$ & -9.655 \\
8 & -3.675 & $4.315 \mathrm{e}-04$ & -9.661 \\
7 & -4.403 & $3.549 \mathrm{e}-05$ & -9.697 \\
6 & -6.497 & $4.840 \mathrm{e}-10$ & -9.706 \\
5 & -4.326 & $4.717 \mathrm{e}-05$ & -9.396 \\
4 & -8.717 & $1.050 \mathrm{e}-23$ & -9.386 \\
3 & -11.733 & $2.138 \mathrm{e}-93$ & -9.287 \\
2 & -52.557 & $0.000 \mathrm{e}+00$ & -9.057 \\
1 & -7.854 & $1.370 \mathrm{e}-16$ & -5.852 \\
0 & -17.940 & $0.000 \mathrm{e}+00$ & -5.857 \\
\hline
\end{tabular}

obtained an initial model with 40 variables - 1 dependent variable (ln $I m$ ), 35 in-

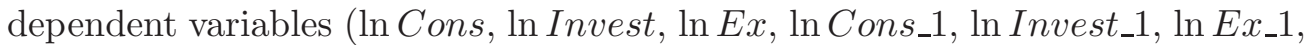
$\ln I m_{-} 1, \ln C o n s \_2, \ln$ Invest_2, $\ln E x_{\_} 2, \ln I m_{-} 2, \ln C o n s \_3, \ln$ Invest_3, $\ln E x_{\_} 3$, $\ln I m_{\_} 3, \ln C o n s_{\_} 4, \ln$ Invest_4, ln Ex_4, ln Im_4, ln Cons_5, ln Invest_5, ln Ex_5, ln Im_5, ln Cons_6, ln Invest_6, ln Ex_6, ln Im_6, ln Cons_7, ln Invest_7, ln Ex_7, $\ln I m_{-} 7, \ln C o n s \_8, \ln$ Invest_8, $\left.\ln E x_{-} 8, \ln I m_{-} 8\right)$ and 4 seasonal components (seas, seas_1, seas_2, seas_3).

The results of the OLS method applied to Model 1 are presented in Table 2. The value of $R^{2}$ is an indication that this model describes well the dynamics of the dependent variable. Based on the $F$-statistics we can consider that this model is adequate.

Table 2: The results of the OLS method applied to Model 1

\begin{tabular}{lcccc}
\hline Variable & Coefficient & Std. Error & $t$-value & $p$-value \\
\hline $\ln$ Cons & 0.229 & 0.553 & 0.415 & 0.683 \\
$\ln$ Invest & 0.286 & 0.092 & 3.120 & 0.006 \\
$\ln$ Ex & 0.485 & 0.135 & 3.590 & 0.002 \\
seas & -1.051 & 4.095 & -0.257 & 0.801 \\
seas_1 & -0.903 & 4.114 & -0.219 & 0.829 \\
seas_2 & -0.935 & 4.104 & -0.228 & 0.822 \\
\hline
\end{tabular}

Continued on next page 
Table 2 - Continued from previous page

\begin{tabular}{lcccc}
\hline Variable & Coefficient & Std. Error & $t$-value & $p$-value \\
\hline seas_3 & -0.924 & 4.116 & -0.225 & 0.825 \\
$\ln$ Cons_1 & 0.972 & 0.436 & 2.230 & 0.040 \\
$\ln$ Invest_1 & 0.135 & 0.118 & 1.140 & 0.268 \\
$\ln$ Ex_1 & -0.129 & 0.165 & -0.783 & 0.444 \\
$\ln$ Im_1 & 0.334 & 0.218 & 1.530 & 0.144 \\
$\ln$ Cons_2 & 0.527 & 0.441 & 1.190 & 0.249 \\
$\ln$ Invest_2 & 0.060 & 0.138 & 0.437 & 0.667 \\
$\ln$ Ex_2 & 0.041 & 0.151 & 0.272 & 0.789 \\
$\ln$ Im_2 & -0.214 & 0.221 & -0.966 & 0.348 \\
$\ln$ Cons_3 & 0.007 & 0.457 & 0.015 & 0.988 \\
$\ln$ Invest_3 & 0.045 & 0.126 & 0.360 & 0.723 \\
$\ln$ Ex_3 & 0.076 & 0.159 & 0.477 & 0.639 \\
$\ln$ Im_3 & -0.089 & 0.232 & -0.385 & 0.705 \\
$\ln$ Cons_4 & -1.048 & 0.407 & -2.580 & 0.020 \\
$\ln$ Invest_4 & -0.349 & 0.139 & -2.510 & 0.023 \\
$\ln$ Ex_4 & -0.106 & 0.158 & -0.672 & 0.510 \\
$\ln$ Im_4 & 0.094 & 0.230 & 0.407 & 0.689 \\
$\ln$ Cons_5 & 0.045 & 0.441 & 0.102 & 0.920 \\
$\ln$ Invest_5 & -0.027 & 0.152 & -0.179 & 0.860 \\
$\ln$ Ex_5 & 0.114 & 0.163 & 0.700 & 0.494 \\
$\ln$ Im_5 & 0.168 & 0.253 & 0.666 & 0.514 \\
$\ln$ Cons_6 & -0.627 & 0.418 & -1.500 & 0.152 \\
$\ln$ Invest_6 & -0.011 & 0.119 & -0.090 & 0.929 \\
$\ln$ Ex_6 & -0.099 & 0.190 & -0.518 & 0.611 \\
$\ln$ Im_6 & 0.210 & 0.237 & 0.888 & 0.387 \\
$\ln$ Cons_7 & 0.346 & 0.354 & 0.977 & 0.342 \\
$\ln$ Invest_7 & -0.066 & 0.127 & -0.517 & 0.612 \\
$\ln$ Ex_7 & -0.048 & 0.175 & -0.273 & 0.788 \\
$\ln$ Im_7 & 0.212 & 0.273 & 0.777 & 0.448 \\
$\ln$ Cons_8 & -0.239 & 0.388 & -0.617 & 0.546 \\
$\ln$ Invest_8 & -0.197 & 0.124 & -1.580 & 0.132 \\
$\ln$ Ex_8 & -0.264 & 0.174 & -1.520 & 0.148 \\
$\ln$ Im_8 & 0.186 & 0.214 & 0.871 & 0.396 \\
\hline & $1.000 ;$ & $F(39,17)=1240364$ & \\
\hline & & & & \\
& & & & \\
& & &
\end{tabular}


Figure 2 graphically depicts the actual data vs. fitted data from the initial model - Model 1.

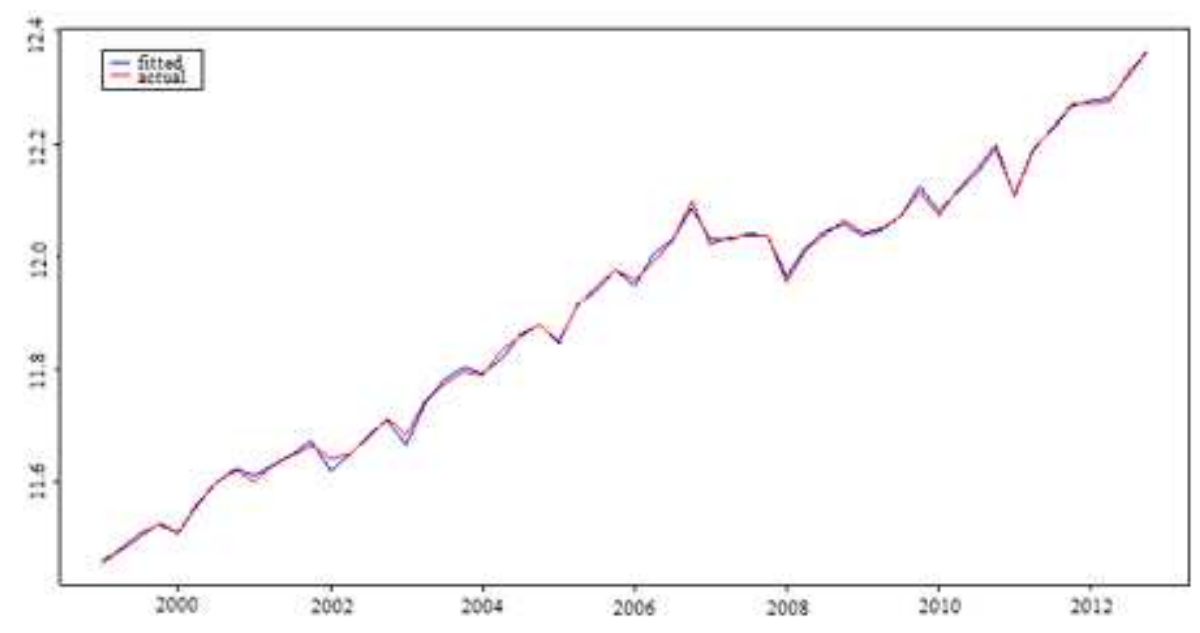

Figure 2: The actual data vs. fitted data from Model 1

In order to use the $t$-statistics to determine the significant variables in Model 1 the assumptions about residuals of a model must be satisfied.

\subsubsection{Checking the Assumptions about Residuals of Model 1}

From the histogram of the residuals (Figure 3) follows that the residuals have a normal distribution. This conclusion was confirmed through normality tests of Jarque-Bera and Doornik-Hansen whose results are 0.115 and 0.137 , respectively.

The graph of the residuals of Model 1 is presented on Figure 4. Due to the presence of the periods in which the residues are systematically positive and periods in which they are systematically negative, we assumed that in Model 1 there is the presence of autocorrelation. To test this, we used BreuschGodfrey test for serial correlation of order 8 and we received the following results: $F=0.900, d f 1=8, d f 2=9, p$-value $=0.554$. Because of the large $p$ value we cannot reject $H_{0}$. Therefore, the residuals of Model 1 are independent.

The scatter plot of the residuals of Model 1 is presented on Figure 5. We assume that there is heteroscedasticity of residuals because there are some places with concentration of the residues. We checked this conclusion by using the White test and we obtained the following results: $X^{2}=56, d f=55$, 


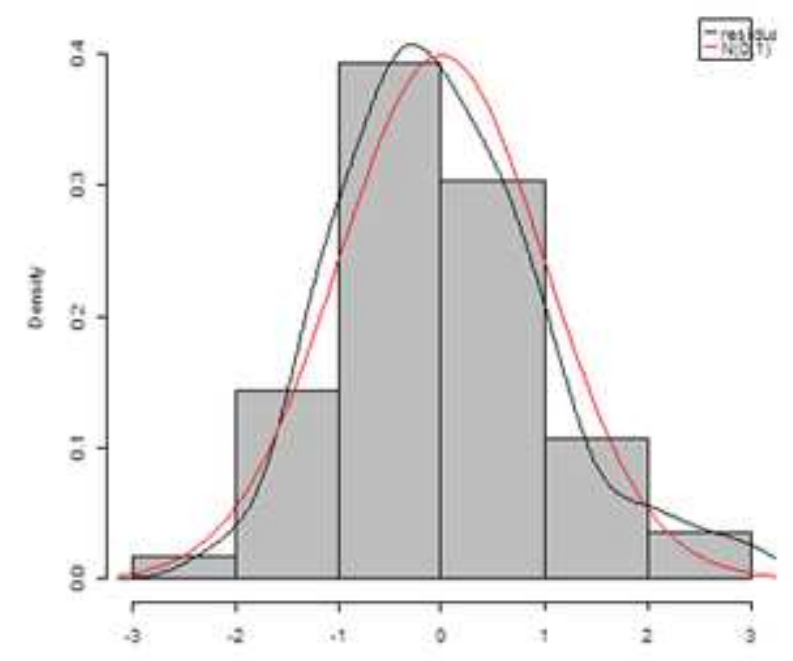

Figure 3: Histogram of residuals of Model 1

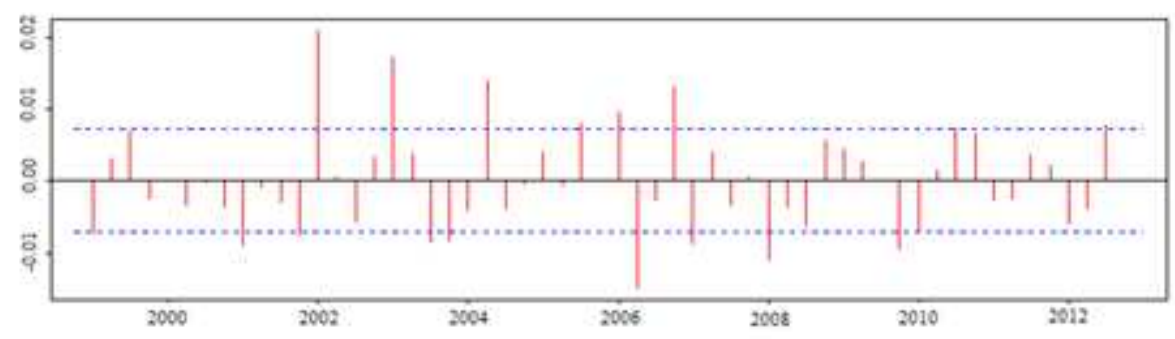

Figure 4: Residuals of Model 1

$p$-value $=0.437$. Due to the large $p$-value, we cannot reject $H_{0}$. Consequently, residuals are equally distributed.

Based on the above conclusions, we accepted that the assumptions about the residuals of Model 1 are satisfied. By using the $t$-statistics and $p$-values in Table 2, we have concluded that only five of all variables in Model 1 are significant - $\ln$ Invest, $\ln$ Ex, ln Cons_1, ln Cons_4 and ln Invest_4. 

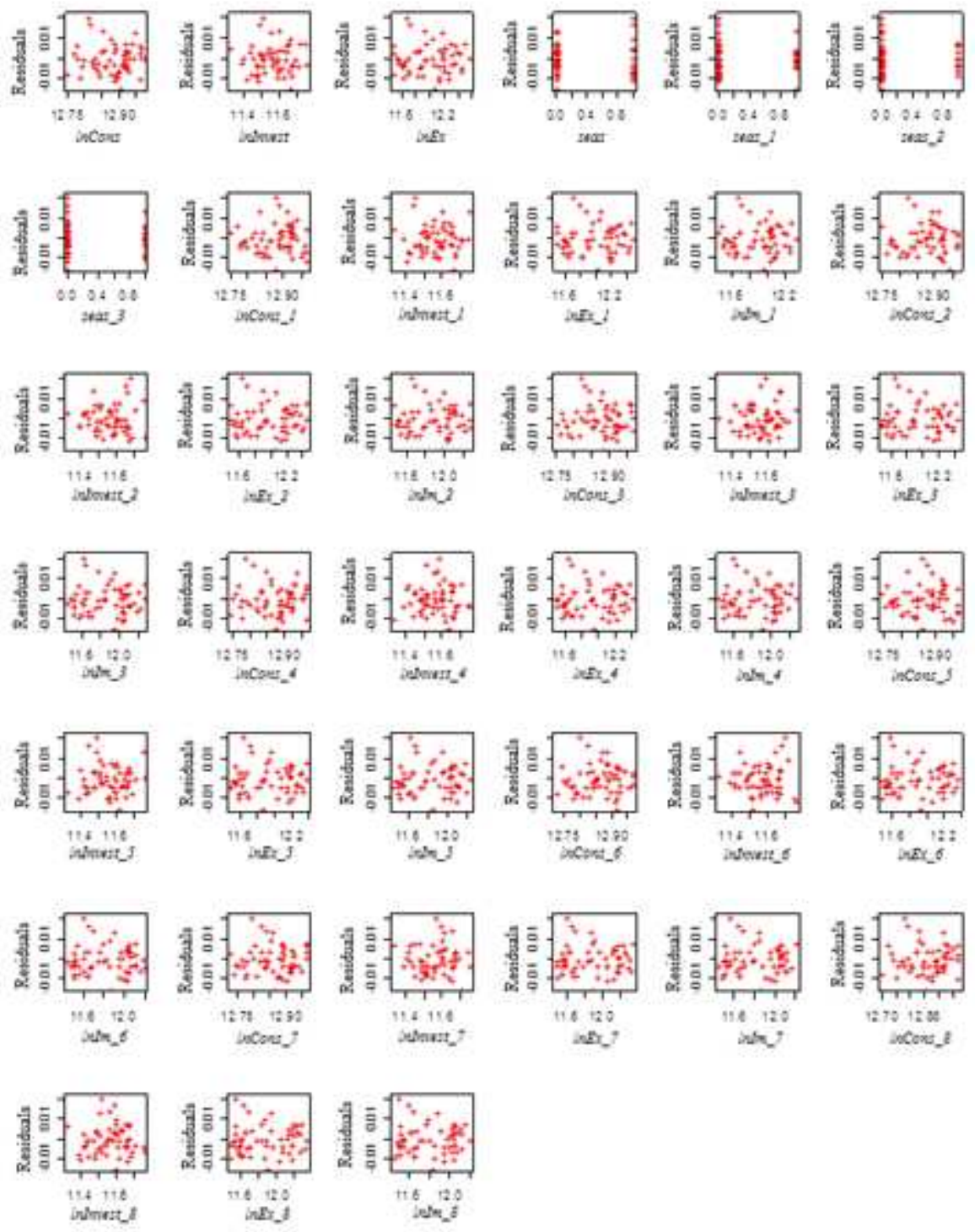

Figure 5: Scatter plot of the residuals of Model 1

\subsection{Reducing Model 1 to a Model with 2 Lags}

The next step in our study is to check whether Model 1 (the model whit 8 lags) can be reduced to a model with fewer lags. For this purpose, by using the Nested 
test we obtained the following results: $F[4,45]=3.043$ and $p$-value $=0.027$. Hence, it is possible to move to a model without lags. But because time series are integrated in first and second order, Model 1 could be reduced to a model with at least 2 lags.

Let us denote as Model 2 the reduced Model 1, i.e. this is the model in which we have added 2 lags to each of the four variables. Therefore, in Model 2 we have the following 16 variables: $\ln$ Cons, $\ln$ Invest, $\ln E x, \ln I m, \ln$ Cons_1, ln Invest_1, ln Ex_1, ln Im_1, ln Cons_2, ln Invest_2, ln Ex_2, ln Im_2, seas, seas_1, seas_2, seas_3. The results of the OLS method applied to Model 2 are presented in Table 3. Based on the values of $R^{2}$ and $F$-statistics we can consider that this model describes well the dynamics of the dependent variable and it is adequate.

Table 3: The results of the OLS method applied to Model 2.

\begin{tabular}{lcccc}
\hline Variable & Coefficient & Std. Error & t-value & p-value \\
\hline $\ln$ Cons & 0.338 & 0.220 & 1.530 & 0.132 \\
$\ln$ Invest & 0.399 & 0.054 & 7.430 & 0.000 \\
$\ln$ Ex & 0.533 & 0.074 & 7.180 & 0.000 \\
seas & -4.543 & 1.697 & -2.680 & 0.010 \\
seas_1 & -4.521 & 1.701 & -2.660 & 0.011 \\
seas_2 & -4.551 & 1.700 & -2.680 & 0.010 \\
seas_3 & -4.483 & 1.702 & -2.630 & 0.011 \\
$\ln$ Cons_1 & 0.286 & 0.231 & 1.240 & 0.221 \\
$\ln$ Invest_1 & -0.057 & 0.080 & -0.707 & 0.483 \\
$\ln$ Ex_1 & -0.048 & 0.113 & -0.427 & 0.671 \\
$\ln$ Im_1 & 0.270 & 0.146 & 1.850 & 0.071 \\
$\ln$ Cons_2 & -0.335 & 0.218 & -1.530 & 0.132 \\
$\ln$ Invest_2 & -0.126 & 0.074 & -1.690 & 0.098 \\
$\ln$ Ex_2 & -0.091 & 0.010 & -0.911 & 0.367 \\
$\ln$ Im_2 & 0.191 & 0.140 & 1.360 & 0.180 \\
\hline & $R^{2}=0.100 ;$ & $F(15,47)=3049182$ & \\
\hline
\end{tabular}

Figure 6 graphically depicts the actual data vs fitted data from Model 2.

\subsubsection{Checking the Assumptions about Residuals of Model 2}

From the histogram of the residuals (Figure 7 ) it follows that the residuals of Model 2 have normal distribution. We confirmed this conclusion through 


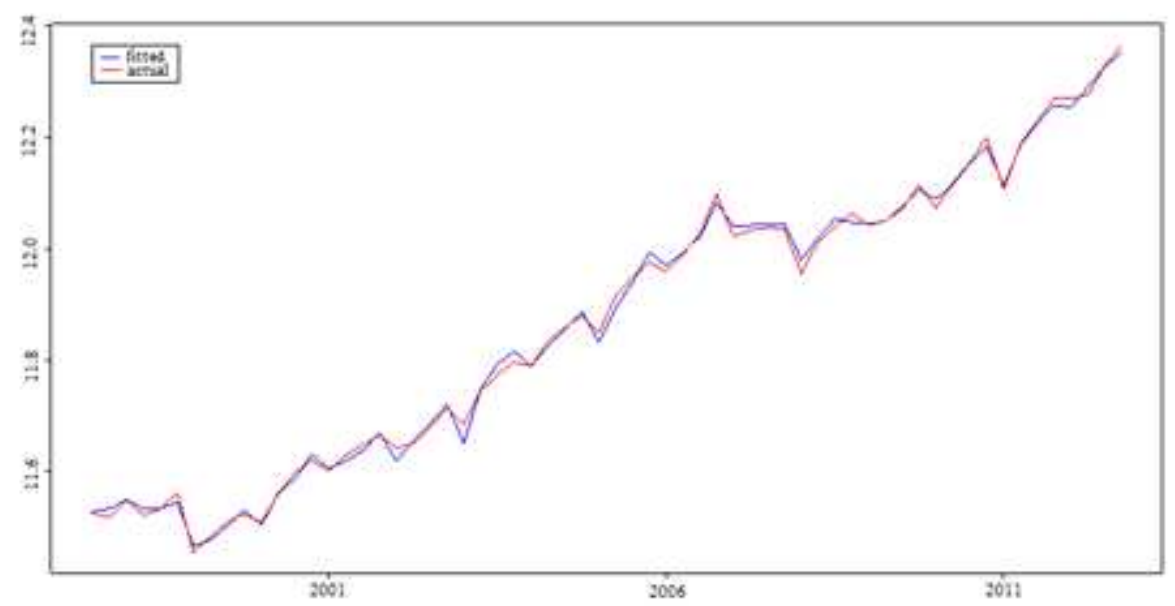

Figure 6: Actual data vs fitted data from Model 2

normality tests of Jarque-Bera and Doornik-Hansen. We received the following results 0.672 and 0.686 , respectively. Let us note that there is a significant improvement in the results of both normality tests compared to the results of Model 1.

The graph of the residuals of Model 2 is presented on Figure 8. Due to the presence of the periods in which the residues are systematically positive and periods in which they are systematically negative, we assumed that in Model 2 there is the presence of autocorrelation. To test this, we used BreuschGodfrey test for serial correlation of order 8 and we received the following results: $F=1.272, d f 1=8, d f 2=39, p$-value $=0.286$. Because of the large $p$ value we cannot reject $H_{0}$. Therefore, the residuals of Model 2 are independent.

The scatter plot of the residuals of Model 2 is presented on Figure 9. We assume that there is heteroscedasticity of residuals because there are some places with a concentration of the residues. This conclusion is not confirmed by the White test from which we have the following results: $X^{2}=25.745, d f=25$, $p$-value $=0.421$. Consequently, residuals are equally distributed.

From the above research we have concluded that the assumptions about the residuals of Model 2 are satisfied. Therefore, we can use $t$-statistics from the OLS method to determine which variables of Model 2 are significant and which are not. As a result, in the Model 2 variables $\ln$ Cons, $\ln$ Cons_1, $\ln$ Invest_1, $\ln E x_{\_} 1, \ln C o n s \_2, \ln E x_{\_} 2, \ln I m_{-} 2$ are non-significant and the rest variables 


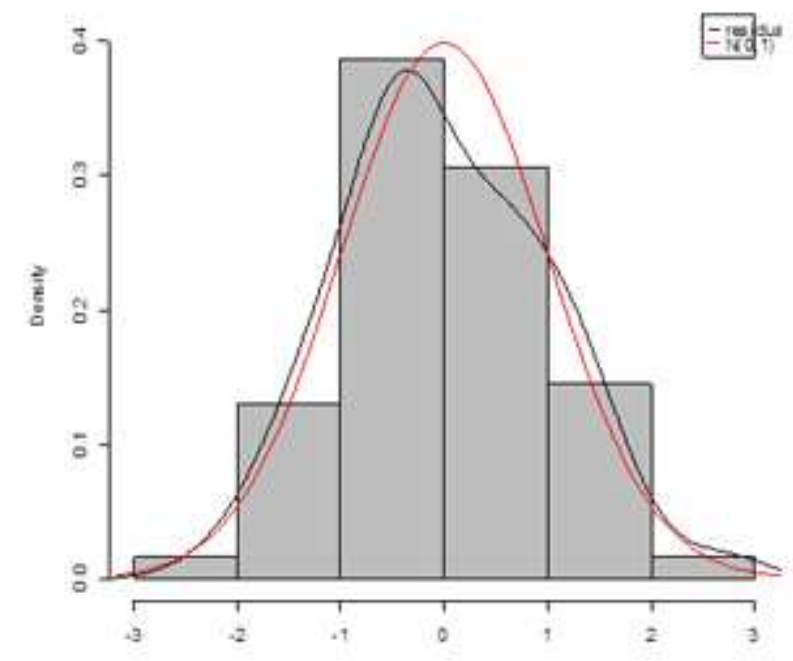

Figure 7: Histogram of residuals of Model 2

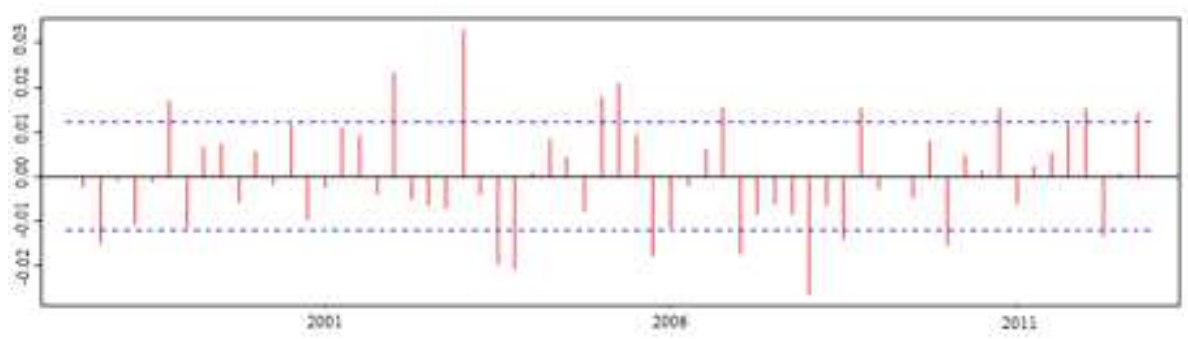

Figure 8: Residuals of Model 2

are significant.

\subsection{Model with Maximum Number of Stationary Time Series}

From the fact that we work with non-stationary time series, $t$-statistics are offset and therefore the significant of the variables can be misleading. Therefore, we created a model in which we replaced all non-stationary time series participating in Model 2 with stationary, generating the first differences of $\ln I m$ and $\ln$ Invest and the second differences of $\ln E x$ and $\ln$ Cons, respectively. The model thus created is denoted as dModel 2. All variables involved in dModel 2 are: $\ln E x$, 

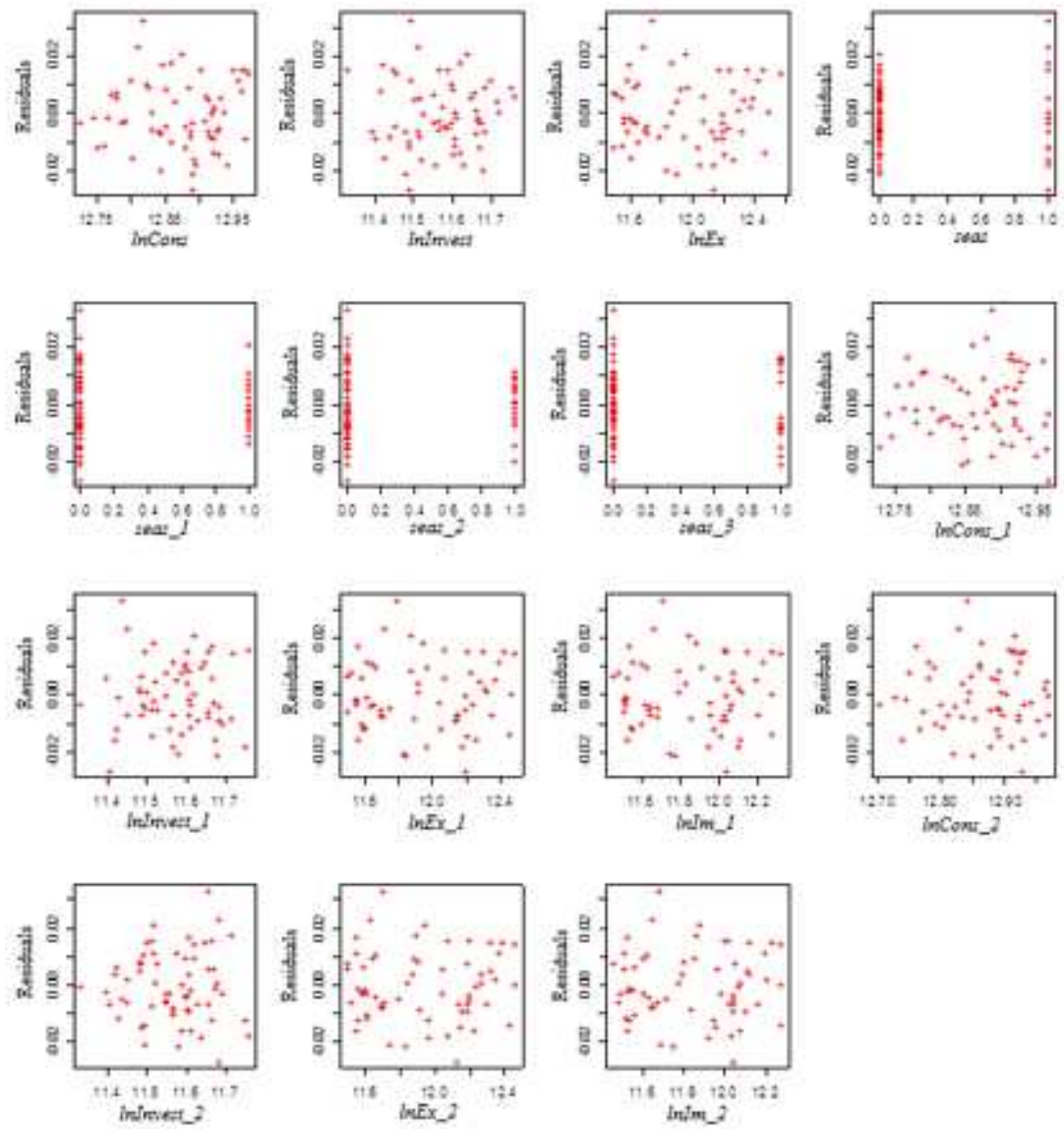

Figure 9: Scatter plot of the residuals of Model 2

$\ln C o n s, \ln E x \_1, \ln C o n s \_1, \ln E x_{\_} 2, \ln C o n s \_2, d \ln E x_{-} 1$, ddln $E x$, dln $C o n s \_1$, ddln Cons, ln Im, ln Im_1, ln Im_2, dln Im, dln Im_1, ln Invest, ln Invest_1, ln Invest_2, dln Invest, dln Invest_1, seas, seas_1, seas_2, seas_3.

Since dModel 2 is equivalent to Model 2, we have concluded that the assumptions about residuals of dModel 2 are satisfied. Then, having in mind the results of the OLS method (Table 4), we have concluded that of all variables involved in the model dModel 2 the only variables ddln Cons and $d \ln I m_{1}$ are non-significant.

Figure 10 graphically depicts the actual data vs. fitted data from model dModel 2. Here the variable dln $I m$ is stationary. 
Table 4: Results of the OLS method applied to dModel 2.

\begin{tabular}{|c|c|c|c|c|}
\hline Variable & Coefficient & Std. Error & $\mathrm{t}$-value & $\mathrm{p}$-value \\
\hline $\mathrm{dd} \ln$ Cons & 0.338 & 0.220 & 1.530 & 0.132 \\
\hline dln Invest & 0.399 & 0.054 & 7.430 & 0.000 \\
\hline $\mathrm{dd} \ln E x$ & 0.533 & 0.074 & 7.180 & 0.000 \\
\hline seas & -4.543 & 1.697 & -2.680 & 0.010 \\
\hline seas_1 & -4.521 & 1.701 & -2.660 & 0.011 \\
\hline seas_2 & -4.551 & 1.700 & -2.680 & 0.010 \\
\hline seas_3 & -4.483 & 1.702 & -2.630 & 0.011 \\
\hline dln Cons_1 & 0.672 & 0.364 & 1.850 & 0.071 \\
\hline dln Invest_1 & 0.126 & 0.074 & 1.690 & 0.098 \\
\hline dln $E x_{-} 1$ & 0.624 & 0.127 & 4.900 & 0.000 \\
\hline dln $I m \_1$ & -0.191 & 0.140 & -1.360 & 0.180 \\
\hline $\ln$ Cons_1 & 0.289 & 0.124 & 2.330 & 0.024 \\
\hline ln Invest_1 & 0.216 & 0.082 & 2.640 & 0.011 \\
\hline $\ln E x_{-} 1$ & 0.394 & 0.126 & 3.130 & 0.003 \\
\hline $\ln I m_{-} 1$ & -0.539 & 0.171 & -3.150 & 0.003 \\
\hline
\end{tabular}

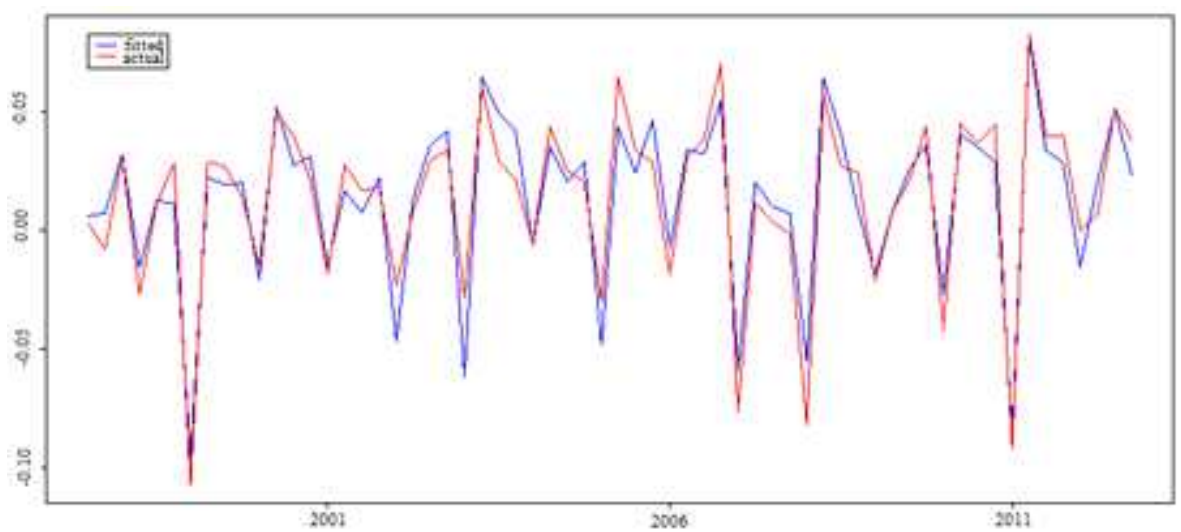

Figure 10: Actual data vs. fitted data from dModel 2

Because we have a small sample to build a statistical model, this could lead to multicollinearity. In this regard, we examined the coefficients of all the variables in the model dModel 2 that are presented in Table 5. 
Table 5: Coefficients of all variables in the model dModel 2.

\begin{tabular}{llll}
\hline Variable & Coefficient & Variable & Coefficient \\
\hline ddln Cons & $9.747 \mathrm{e}+01$ & dln Invest_1 & $3.195 \mathrm{e}+01$ \\
dln Invest & $1.753 \mathrm{e}+01$ & dln Ex_1 & $1.175 \mathrm{e}+01$ \\
ddln Ex & $1.134 \mathrm{e}+01$ & dln Im_1 & $1.006 \mathrm{e}+01$ \\
seas & $2.261 \mathrm{e}+05$ & $\ln$ Cons_1 & $8.236 \mathrm{e}+05$ \\
seas_1 & $2.271 \mathrm{e}+05$ & $\ln$ Invest_1 & $2.903 \mathrm{e}+05$ \\
seas_2 & $2.421 \mathrm{e}+05$ & $\ln$ Ex_1 & $7.3223 \mathrm{e}+05$ \\
seas_3 & $2.425 \mathrm{e}+05$ & $\ln$ Import_1 & $1.337 \mathrm{e}+06$ \\
dlnCons_1 & $8.520 \mathrm{e}+01$ & & \\
\hline
\end{tabular}

Since there are values exceeding 10, we concluded that there is multicollinearity between the independent variables. This fact could be avoided by removing the non-significant variables from the model. For this purpose, using the model dModel 2 by sequentially removing the non-significant variables (those with the large $p$-value), we created 4 sub-models. We evaluated each of them by the OLS method and the results are presented in Table 6 .

Table 6: Results of the OLS method applied to the four sub-models of dModel 2.

\begin{tabular}{lcccc}
\hline Name & Coeff. & Std. Error & $t$-value & $p$-value \\
\hline \multicolumn{4}{c}{ dModel 2_1 } \\
ddln Cons & 0.386 & 0.219 & 1.760 & 0.085 \\
dln Invest & 0.397 & 0.054 & 7.320 & 0.000 \\
ddln Ex & 0.548 & 0.074 & 7.420 & 0.000 \\
seas & -5.547 & 1.542 & -3.600 & 0.001 \\
seas_1 & -5.519 & 1.548 & -3.560 & 0.001 \\
seas_2 & -5.552 & 1.546 & -3.590 & 0.001 \\
seas_3 & -5.489 & 1.547 & -3.550 & 0.001 \\
dln Cons_1 & 0.632 & 0.366 & 1.730 & 0.091 \\
dln Invest_1 & 0.055 & 0.054 & 1.020 & 0.312 \\
dln Ex_1 & 0.543 & 0.114 & 4.780 & 0.000 \\
ln Cons_1 & 0.355 & 0.115 & 3.100 & 0.003 \\
ln Invest_1 & 0.266 & 0.074 & 3.610 & 0.001 \\
\hline
\end{tabular}

Continued on next page 
Table 6 - Continued from previous page

\begin{tabular}{lcccc}
\hline Name & Coeff. & Std. Error & $t$-value & $p$-value \\
\hline $\ln$ Ex_1 & 0.491 & 0.105 & 4.690 & 0.000 \\
$\ln$ Im_1 & -0.673 & 0.141 & -4.770 & 0.000 \\
& $R^{2}=0.905 ;$ & $F(14,48)$ & $=33$ \\
\hline \multicolumn{5}{c}{ dModel $2 \_2$} \\
ddln Cons & 0.346 & 0.216 & 1.600 & 0.116 \\
dln Invest & 0.385 & 0.053 & 7.270 & 0.000 \\
ddln Ex & 0.555 & 0.074 & 7.540 & 0.000 \\
seas & -5.525 & 1.542 & -3.580 & 0.001 \\
seas_1 & -5.482 & 1.549 & -3.540 & 0.001 \\
seas_2 & 5.517 & 1.547 & -3.570 & 0.001 \\
seas_3 & -5.454 & 1.547 & -3.530 & 0.001 \\
dlnCons_1 & 0.566 & 0.361 & 1.570 & 0.123 \\
dln Ex_1 & 0.557 & 0.113 & 4.940 & 0.000 \\
$\ln$ Cons_1 & 0.337 & 0.114 & 2.970 & 0.005 \\
$\ln$ Invest_1 & 0.281 & 0.072 & 3.900 & 0.000 \\
$\ln$ Ex_1 & 0.498 & 0.104 & 4.770 & 0.000 \\
$\ln$ Im_1 & -0.678 & 0.141 & -4.800 & 0.000 \\
ddln Cons & 0.346 & 0.216 & 1.600 & 0.116 \\
& $R^{2}=0.903 ;$ & $F(13,49)$ & $=35$ & \\
\hline
\end{tabular}

dModel 2_3

\begin{tabular}{|c|c|c|c|c|}
\hline ddln Cons & 0.057 & 0.114 & 0.496 & 0.622 \\
\hline dln Invest & 0.386 & 0.054 & 7.190 & 0.000 \\
\hline ddln $E x$ & 0.572 & 0.074 & 7.730 & 0.000 \\
\hline seas & -5.784 & 1.556 & -3.720 & 0.001 \\
\hline seas_1 & -5.751 & 1.561 & -3.680 & 0.001 \\
\hline seas_2 & -5.767 & 1.561 & -3.700 & 0.001 \\
\hline seas_3 & -5.698 & 1.562 & -3.650 & 0.001 \\
\hline dln $E x_{1} \_1$ & 0.592 & 0.112 & 5.280 & 0.000 \\
\hline $\ln$ Cons_1 & 0.337 & 0.115 & 2.920 & 0.005 \\
\hline $\ln$ Invest_1 & 0.316 & 0.070 & 4.520 & 0.000 \\
\hline $\ln E x_{-} 1$ & 0.531 & 0.104 & 5.110 & 0.000 \\
\hline $\ln I m \_1$ & -0.723 & 0.141 & -5.140 & 0.000 \\
\hline ddln Cons & 0.057 & 0.114 & 0.496 & 0.622 \\
\hline dln Invest & 0.386 & 0.054 & 7.190 & 0.000 \\
\hline
\end{tabular}


Table 6 - Continued from previous page

\begin{tabular}{|c|c|c|c|c|}
\hline Name & Coeff. & Std. Error & $t$-value & $p$-value \\
\hline \multicolumn{5}{|c|}{$R^{2}=0.898$} \\
\hline \multicolumn{5}{|c|}{ dModel 2_3 } \\
\hline dln Invest & 0.387 & 0.053 & 7.260 & 0.000 \\
\hline ddln $E x$ & 0.577 & 0.073 & 7.960 & 0.000 \\
\hline seas & -5.629 & 1.513 & -3.720 & 0.000 \\
\hline seas_1 & -5.585 & 1.514 & -3.690 & 0.001 \\
\hline seas_2 & -5.607 & 1.516 & -3.700 & 0.001 \\
\hline seas_3 & -5.534 & 1.515 & -3.650 & 0.001 \\
\hline dln $E x \_1$ & 0.601 & 0.110 & 5.470 & 0.000 \\
\hline $\ln C o n s \_1$ & 0.323 & 0.111 & 2.910 & 0.005 \\
\hline ln Invest_1 & 0.314 & 0.069 & 4.540 & 0.000 \\
\hline $\ln E x \_1$ & 0.529 & 0.103 & 5.140 & 0.000 \\
\hline $\ln I m \_1$ & -0.718 & 0.139 & -5.160 & 0.000 \\
\hline dln Invest & 0.387 & 0.053 & 7.260 & 0.000 \\
\hline $\mathrm{dd} \ln E x$ & 0.577 & 0.073 & 7.960 & 0.000 \\
\hline \multirow[t]{2}{*}{ seas } & -5.629 & 1.513 & -3.720 & 0.000 \\
\hline & $R^{2}=0.898$ & $F(11,51$ & $=41$ & \\
\hline
\end{tabular}

We examined the possibility of reducing the model dModel 2 to a model with fewer variables (i.e. to one of the four sub-models) by using the Nested test. Based on the obtained results presented in Table 7, we reduced the model dModel 2 to a model dModel 2_4.

Due to the fact that the dModel 2_4 model is not equivalent to the dModel 2 model, it is necessary to verify that the assumptions about residuals of dModel 2_4 are satisfied.

\subsubsection{Checking the Assumptions about Residuals of dModel 2_4}

Figure 11 graphically depicts the actual data vs fitted data from dModel 2_4.

From the histogram (Figure 12) it follows that the residuals of dModel 2_4 have a normal distribution. This conclusion is also confirmed by the normality tests of Jarque-Bera and Doornik-Hansen whose results are 0.969 and 0.895 , respectively.

The graph of the residuals of dModel 2_4 is presented on Figure 13. Due to the presence of the periods in which the residues are systematically positive and 
Table 7: Results of the Nested test applied to dModel 2.

\begin{tabular}{lll}
\hline Model Name & F - stat. & $p$-value \\
\hline dModel 2 $\rightarrow$ dModel 2_1 & 1.854 & 0.180 \\
dModel $2 \rightarrow$ dModel 2_2 & 1.458 & 0.243 \\
dModel 2 $\rightarrow$ dModel 2_3 & 1.808 & 0.159 \\
dModel 2 $\rightarrow$ dModel 2_4 & 1.421 & 0.242 \\
dModel 2 $\rightarrow$ dModel 2_2 & 1.043 & 0.312 \\
dModel 2_1 $\rightarrow$ dModel 2_3 & 1.754 & 0.184 \\
dModel 2_1 $\rightarrow$ dModel 2_4 & 1.254 & 0.301 \\
dModel 2_2 $\rightarrow$ dModel 2_3 & 2.463 & 0.123 \\
dModel 2_2 $\rightarrow$ dModel 2_4 & 1.358 & 0.267 \\
dModel 2_3 $\rightarrow$ dModel 2_4 & 0.246 & 0.622 \\
\hline
\end{tabular}

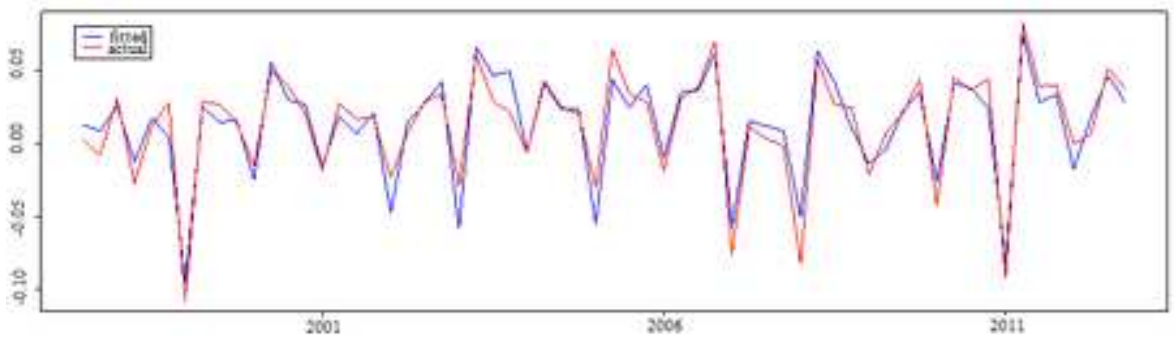

Figure 11: Actual data vs. fitted data from dModel 2_4

periods in which they are systematically negative, we assumed that in dModel 2_4 there is autocorrelation. This result is not confirmed by the BreuschGodfrey test for serial correlation of order 8 whose results are: $F=0.905$, $d f 1=8, d f 2=43, p$-value $=0.521$. Therefore, the residuals of dModel 2_4 are independent.

The scatter plot of the residuals of dModel 2_4 is presented on Figure 14. We assumed that there is heteroscedasticity of residuals because there are some places with concentration of residues. This conclusion is not confirmed by the White test the results of which results are: $X^{2}=25.025, d f=17, p$-value $=$ 0.094. Consequently, residuals are equally distributed.

Based on the above conclusions, we accepted that the assumptions about the residuals of dModel 2_4 are satisfied. Then, by using the $t$-statistics and $p$-values in Table 6, we have concluded that all variables in dModel 2_4 are 


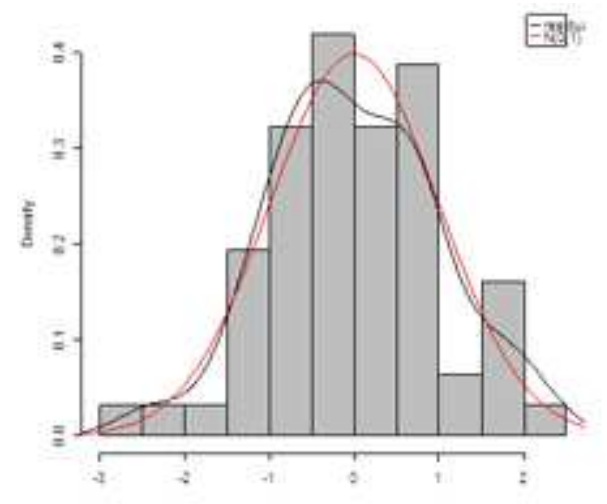

Figure 12: Histogram of residuals of dModel 2_4

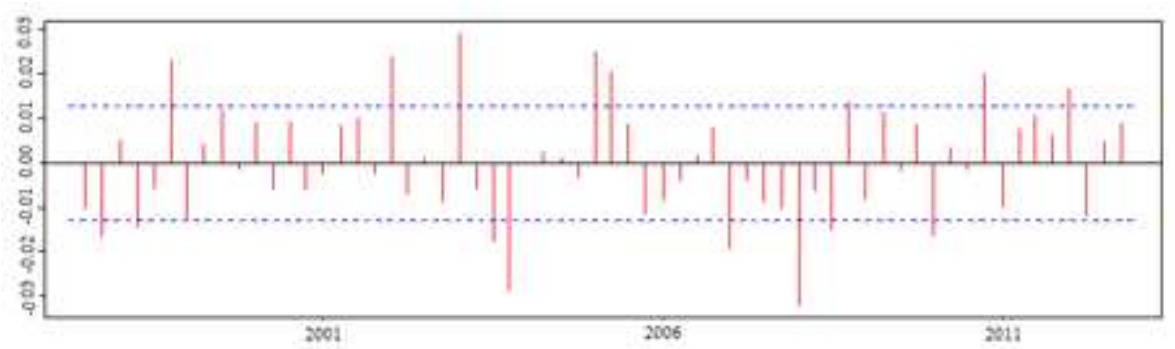

Figure 13: Residuals of dModel 2_4

significant. To test whether multicollinearity exists in dModel 2_4, we studied the coefficients in front of all the variables which are presented in Table 8.

Table 8: Coefficients of all variables in the model dModel 2_4.

\begin{tabular}{llll}
\hline Variable & Coefficient & Variable & Coefficient \\
\hline dln Invest & $1.674 \mathrm{e}+01$ & dln Ex_1 & $8.441 \mathrm{e}+00$ \\
ddln Ex & $1.051 \mathrm{e}+01$ & $\ln$ Cons_1 & $6.418 \mathrm{e}+05$ \\
seas & $1.739 \mathrm{e}+05$ & $\ln$ Invest_1 & $2.010 \mathrm{e}+05$ \\
seas_1 & $1.741 \mathrm{e}+05$ & $\ln$ Ex_1 & $4.748 \mathrm{e}+05$ \\
seas_2 & $1.862 \mathrm{e}+05$ & $\ln$ Import_1 & $8.545 \mathrm{e}+05$ \\
seas_3 & $1.860 \mathrm{e}+05$ & & \\
\hline
\end{tabular}



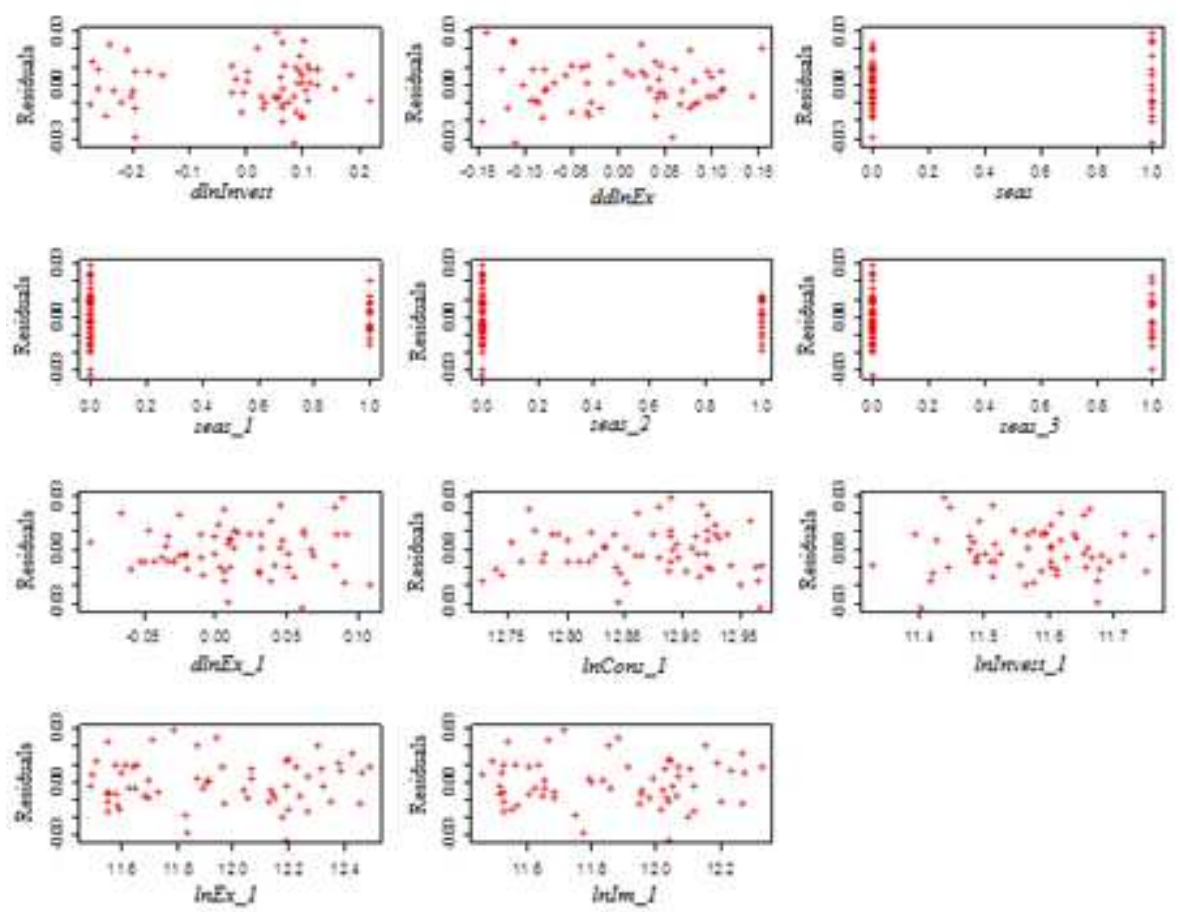

Figure 14: Scatter plot of the residuals of of dModel 2_4

Since there are values exceeding 10 , we concluded that there is multicollinearity between the independent variables. This is probably due to the fact that we have a small sample. However, the absolute value of $t$-statistics is greater than 2 , so we can do nothing to remove multicollinearity.

Thus, using the estimated model dModel 2_4 we have the following equation for the dependent variable:

$$
\begin{aligned}
\mathrm{d} \ln I m_{t} & =0.387 \mathrm{~d} \ln \text { Invest }_{t}+0.577 \mathrm{dd} \ln E x_{t} \\
& +0.601 \mathrm{~d} \ln E x_{t-1}+0.323 \ln \text { Cons }_{t-1}+0.314 \ln \text { Invest }_{t-1} \\
& +0.529 \ln E x_{t-1}-0.718 \ln \text { Im }_{t-1}-5.629 \text { seas }-5.585 \text { seas_1 } \\
& -5.607 \text { seas_ } 2-5.534 \text { seas_ } 3+\varepsilon_{t}
\end{aligned}
$$

This equation can be overwritten in the terms of an error correction model 
as:

$$
\begin{aligned}
\mathrm{d} \ln I m_{t}= & 0.387 \mathrm{~d} \ln \text { Invest }_{t}+0.577 \mathrm{dd} \ln E x_{t} \\
- & 0.718\left(\ln \text { Im }_{t-1}-0.837 \mathrm{~d} \ln E x_{t-1}-0.450 \ln \text { Cons }_{t-1}\right. \\
& \left.\quad-0.437 \ln \text { Invest }_{t-1}-0.737 \ln E x_{t-1}\right) \\
& -5.629 \text { seas }-5.585 \text { seas_ } 1-5.607 \text { seas_2 }-5.534 \text { seas_ } 3+\varepsilon_{t},
\end{aligned}
$$

where the short-term effects are recorded on the first line, on the second and third - the long-term and on the fourth - the seasonal components.

\section{Conclusion}

This study examines the dependence of imports on consumption, investment and exports in Germany by using time series data for the period 1997-2013. We received an error correction model that involved short-term and long-term effects and seasonal components. Based on the estimated model, we can make the following interpretations:

- If the investments increase by $1 \%$, the short-term effect of this increase would result in an increase in imports by $0.39 \%$;

- If exports increase by $1 \%$, the short-term effect of this increase would result in an increase in imports by $0.58 \%$;

- We determined a period of 1.4 quarters for which there would be a balance of imports in case of shock on independent variables;

- There is also a slight constant change in imports during different seasons and a general reduction of import growth by $5.59 \%$ on average.

\section{References}

[1] A.J. Abbott, H.R. Seddighi, Aggregate imports and expenditure components in the UK: an empirical analysis, Appl. Econ., 28 (1996), 1119-25.

[2] F.G. Adams, H. Eguchi, F. Meyer-Zuschlochtern, An Econometric Analysis of International Trade, OECD, Paris (1969).

[3] P.S. Armington, Adjustment of Trade Balances: Some Experience with a Model of Trade Among Many Countries, IMF Staff Papers, 17 (1970), 488-526.

[4] J. Asafu-Adjaye, D. Chakraborty, Exportled Growth and Import Compression: Further Time Series Evidence From LDCs, Aust. Econ. Pap., 38 (1999), 164-75. 
[5] M. Beenstock, P. Minford, A Quarterly Econometric Model of Trade and Prices, In: Inflation in Open Economies, Manchester University Press, Manchester (1976), 1955-71.

[6] T.S. Breusch, Testing for Autocorrelation in Dynamic Linear Models, Aust. Econ. Pap., 17 (1978), 334-355.

[7] T. Chang, Y.-H. Ho, C.-J. Huang, A Reexamination Of South Korea's Aggregate Import Demand Function: The Bounds Test Analysis, JED, 30 (2005), 119-128.

[8] A.K. Dash, An Econometric Estimation of the Aggregate Import Demand Function for India, Aryan Hellas Ltd (2005).

[9] D.A. Dickey, W.A. Fuller, Distribution of the Estimators for Autoregressive Time Series with a Unit Root, J. Am. Stat. Assoc., 74 (1979), 427-431.

[10] J.J. Dolado, J. Gonzalo, F. Marmol, Cointegration, Manage Decis. Econ., 23 (1999), 439-446.

[11] J.A. Doornik, H. Hansen, An Omnibus Test for Univariate and Multivariate Normality, Working Paper, Nuffield College, Oxford University, Oxford, U.K (1994).

[12] D. Dutta, N. Ahmed, An Aggregate Import Demand Function For Bangledes: A Cointegration Approach, Appl. Econ., 31 (1999), 465-472.

[13] J. Gafar, Some Estimates Of The Price And Income Elasticities Of Import Demand For Three Caribbean Countries, Appl. Econ., 27 (1995), 1045-1048.

[14] G. Gandolfo, M.L. Petit, The Functional Form of the Aggregate Import Demand Equation, Italy, Economic Letters, 2 (1983), 145-148.

[15] M. Ghorbani, M. Motalleb, Application Pesaran and Shin Method For Estimating Irans'Import Demand Function, J. Applied Sci., 9 (2009), 1175-1179.

[16] L.G. Godfrey, Testing Against General Autoregressive and Moving Average Error Models when the Regressors Include Lagged Dependent Variables, Econometrica, 46 (1978), 1293-1301.

[17] M. Goldstein, M.S. Khan, Income and Price Effects in Foreign Trade, In: Handbook of International Economics, North-Holland, Amsterdam (1985), 1041-1105.

[18] H.S. Houthakker, S.P. Magee, Income and Price Elasticities in World Trade, Rev. Econ. Stat., 51 (1969), 111-125.

[19] J.J. Hughes, A.P. Thirlwall, Tends and Cycles in Import Penetration in the UK, Oxf. Bull. Econ. Stat., 4 (1979), 301-318.

[20] Q.M. Hye, M. Mashkoor, Import Demand Function For Bangladesh: A Rolling Window Analysis, AJBM, 4 (2010), 2150-2156.

[21] C. Jarque, A. Bera, Efficient tests for normality, homoscedasticity and serial independence of regression residuals, Economics Letters, 6 (1980), 255-259.

[22] M.S. Khan, K.Z. Ross, Cyclical and Secular Income Elasticity of Demand for Imports, Rev. Econ. Stat., 75 (1975), 221-224.

[23] M.S. Khan, K.Z. Ross, The Functional Form of the Aggregate Import Demand Function, J. Int. Econ., 7 (1977), 149-160.

[24] M.S. Khan, M.D. Knight, Import Compression and Export Performance in Developing Countries, Rev. Econ. Stat., 70 (1988), 315-321. 
[25] A. King, The Functional Form of Import Demand: The Case of UK Motor Vehicle Imports, 1980-90, J. Econ. Stud., 20 (1993), 36-50.

[26] Y. Li, Z. Chen, C. San, Research on the Relationship between Foreign Trade and the GDP Growth of East China - Empirical Analysis Based on Causality, Modern Economy, 1 (2010), 118-124.

[27] B.S. Min, H.A. Tang, T.C. Tang, An analysis of South Korea's import demand, Journal of Asia-Pacific Affairs, 4 (1988), 1-17.

[28] N.C. Modeste, An Empirical Analysis of the Demand for Importsin Three CARICOM Member Countries: An Application of the Bounds Test for Cointegration, Rev. Black Polit. Econ., 38 (2011), 53-62.

[29] T. Murray, P.J. Ginman, An Empirical Examination of the Traditional Aggregate Import Demand Model, Rev. Econ. Stat., 58 (1976), 75-80.

[30] S. Narayan, K. Narayan, An empirical analysis of Fiji's import demand Function, J. Econ. Stud., 32 (2005), 158-168.

[31] M.H. Pesaran, Y. Shin, R.J. Smith, Bounds testing approaches to the analysis of level relationships, Journal of Applied Econometrics, 16 (2001), 289326.

[32] F.F.R. Ramos, Exports, imports, and economic growth in Portugal: evidence from causality and cointegration analysis, Econ. Model., 18 (2002), 613-623.

[33] I.F. Razafimahefa, S. Hamori, Import Demand Function Some Evidence from Madagascar and Mauritius, J. Afr. Econ., 14 (2005), 411-434.

[34] R. Rees, P. Layard, Determinants of U.K. Imports, Covernment Economic Service Occasional Paper 3, London, H.M.S.O. (1974).

[35] H.U. Rehman, An Econometric Estimation Of Traditional Import Demand Function For Pakistan, Pak. Econ. Soc. Rev., 45 (2007), 245-256.

[36] R.M. Stern, C.F. Baum, M.N. Greene, Evidence on Structural Change in the Demand for Aggregate U.S. Imports and Exports, J. Polit. Econ., 87 (1979), 179-192.

[37] T.C. Tang, Aggregate Import Demand Behavior For Indonesia: Evidence From Bounds Testing Approach, IIUM Journal of Economics and Management, 10 (2002a), 1-21.

[38] T.C. Tang, An Aggregate Import Demand Function For Hong Kong, China: New Evidence From The Bounds Test, IJM, 19 (2002b), 561-567.

[39] T.C. Tang, An Empirical Analysis Of China's Aggregate Import Demand Function, China Econ. Rev., 14 (2003), 142-163.

[40] R. Thaver, E.M. Ekanayake, The Impact of Apartheid and International Sanctuions on South Africa's Import Demand Fuction: An Emipirical Analysis, IJBFR, 4 (2010), 11-22.

[41] J. Thursby, M. Thursby, How Reliable are Simple Equation Specifications of Import Demand?, Rev. Econ. Stat., 66 (1984), 772-790.

[42] J.P. Urbain, Error Correction Models for Aggregate Imports: The Case of Two Small and Open Economies, In: International Trade Modelling, Chapman and Hall, London (1992), 237-278.

[43] H. White, A Heteroskedasticity-Consistent Covariance Matrix Estimator and a Direct Test for Heteroskedasticity, Econometrica, 48 (1980), 817-838. 
